\title{
'Se Necesita Encontrar las Palabras para Decirlo' La Marginalización de la Geografía de Género y de la Sexualidad en Italia: Entrevista con Rachele Borghit
}

\author{
Cesare Di Feliciantonio \\ Sapienza - Università di Roma
}

Si a nivel internacional en el último decenio la geografía de género $y$ de las sexualidades fueron promotoras de una fuerte renovación y contaminación al interior de la disciplina geográfica, en Italia género y sexualidad son dos campos de análisis y de investigación poco visibles y practicados. Por ejemplo esta legitimada, aunque de forma marginal y 'para entendidos' en la materia, una visión en este campo que concierne explícitamente a las mujeres y que debe, por esto, ser practicado únicamente por mujeres.

Una de las rarísimas excepciones a esta situación de invisibilidad es representada por Rachele Borghi, geógrafa que ha realizado su doctorado en la universidad de Venecia con una tesis en geografía poscolonial basada sobre la ciudad de Marrakech y la herencia colonial en la planificación contemporánea. Además de haber coordinado publicaciones (Geografia di genere con Antonella Rondinone y Turismo Critico con Filippo Celata), es autora de numerosas publicaciones en el ámbito de la geografía urbana y del turismo con una fuerte atención a las performances (culturales, de género, étnicas, etc.). En los últimos años su trabajo se ha focalizado mayormente sobre sexualidad y ruptura de la héteronormatividad en los espacios urbanos, profundizando el análisis de las performances postporno. Después de haber desempeñado por algunos años la actividad de investigadora (precaria) en Italia, desde el comienzo del 2012 se mudó a Francia, donde actualmente realiza un post-doc ${ }^{2}$ en la Universidad de Rennes.

Cesare Di Feliciantonio: Casi 20 años separan Geografia al femminile (1990) de Arena, primera monografía en lengua italiana de geografía de las mujeres, de Geografia di genere (2009) publicación que coordinaste junto a Antonella Rondinone, en la cual han traducido algunos ensayos fundamentales de la geografía de género internacionales. ¿Cómo considerarías desde entonces la geografía de género en Italia? y ¿Cuáles fueron los momentos fundamentales?

Rachele Borgh: Se trata de un recorrido bastante chato, en efecto Geografia al femminile era sinónimo de geografía de las mujeres y las publicaciones que siguieron continuaron tratando a las mujeres como única población de referencia. Efectivamente, la primera publicación en italiano que ha puesto en discusión la masculinidad llega solamente en el 2007 (DELL'AGNESE y RUSPINI, 2007) y se trata, no por casualidad, de una publicación interdisciplinaria en la cual muchas de las comunicaciones no son obras de geografía. Se debe reconocer como, al interior de la geografía italiana, hubieron etapas importantes para que la geografía de género conquistase un rol, o al menos una cierta legitimidad. Por ejemplo, en 1993, en Cagliari, en el marco del seminario internacional de geografía de la población, Gisella Cortesi y Maria Luisa Gentileschi han organizado un laboratorio sobre el rol del componente femenino en las organizaciones territoriales. Se trata de un momento importante porque era un proyecto financiado por el Ministerio de Educación $^{3}$, que sucesivamente dio lugar a una publicación (CORTESI y GENTILESCHI, 1996). Desde mi punto de vista, y sucesivamente, desde los primeros años del siglo XXI la geografía de género ha comenzado a tener un rol, o al menos a delinearse, como una sub-disciplina, en cuanto algunas geógrafas han comenzado a definirse (también) como geógrafas de género, ¡obviamente las que trabajan sobre esta temática eran solo mujeres! En el 2003 la Società Geografica Italiana ha acogido el seminario del IGU 'Gendered Cities', que ha llevado a una publicación (CORTESI, CRISTALDI and DROOGLEEVER FORTUIJN, 2004) de la cual en el 2006 salió la traducción en italiano, con el titulo, La città delle donne $^{4}$, que era muy diferente a la original. En mi opinión, esto representó un paso atrás, como tal el título de un texto tiene una importancia fundamental. Este es uno de los ejemplos que demuestran bien como en la geografía italiana no se planteó el problema de la distinción entre 'género' y 'mujer', aunque sí en realidad en el interior de este texto estaba contextualizado el debate sobre género dentro de la academia anglosajona; a pesar de esto, se continuó considerando una geografía de mujeres. Dentro de esta reconstrucción cronológica, otra etapa importante es en el 2005, cuando en respuesta a un llamado de la 
AGEI (Associazione dei Geografi Italiani) ${ }^{5}$, Elena Dell'Agnese, Marcella Schmidt di Friedberg, Gisella Cortesi y yo misma dimos a luz un grupo 'Geografía y género', el cual lamentablemente, después de un inicio positivo, no alcanzó jamás a despegar. Efectivamente, si para mí, y alguna más, este grupo tenía una importante función política de hacer presión a la academia, para las demás representaba solo la ocasión de juntar la investigación con un enfoque de género, en particular el que concierne a las mujeres. Los resultados de este grupo se concretizan con la realización de un número monográfico de la revista Geotema (n. 33, 2007), en el cual la coordinadora, Gisella Cortesi, ha reconstituido el estado de la geografía de género en Italia y su retraso en el contexto internacional. En efecto, en el mismo año salieron el numero monográfico de Belgeo, dirigido por María Dolores García Ramón y Janice Monk, dedicado enteramente a la geografía de género en los diferentes contextos nacionales, en el cuál no se escribió nada sobre Italia. Con la voluntad de continuar lo comenzado, le propuse a Antonella Rondinone coordinar una antología en la cual traducir al italiano textos que para nosotros eran fundamentales en la geografía de género a nivel internacional, acompañados de una introducción original en la cual se reconstruía el debate sobre este tema específico. Este proyecto respondía a una doble finalidad política de intentar crear un grupo, relatando así la importancia de un trabajo colectivo, y de reconocer la importancia de la traducción. Efectivamente, desde mi punto de vista es necesario 'encontrar las palabras para decirlo', es decir encontrar y crear el lenguaje vehiculador del mensaje dentro del contexto académico. De esta manera, en el 2009 fue publicado en Geografia di genere pero no tuvo ningún impacto, jal contrario fuimos criticadas porque no nos referimos a la geografía italiana! Aunque fue adoptado como libro de texto en algunos cursos universitarios (en Palermo, Milán, Udine), pero fue sobretodo criticado $\mathrm{y}$, me atreveré a decir, ¡verdaderamente boicoteado!

CDF: En el 2011 has coordinado, junto a Marcella Schmidt di Friedberg, el número especial del Bollettino della Società Geografica Italiana ${ }^{6}$ intitulado Lo spazio della differenza, primera publicación geográfica científica relevante en lengua italiana, focalizada de manera específica en la sexualidad y el deseo. ¿Querrías contarnos la génesis de la publicación y cuáles fueron las reacciones que suscitó? Además ¿esta publicación ha llevado a adquirir un cierto reconocimiento dentro de la geografía italiana?
RB: Este número especial nace con la voluntad de publicar los actos de convenio Lo spazio della differenza organizado en octubre del 2010 en la Universidad de Milán-Bicocca. El objetivo era organizar un convenio internacional en Italia para hacer en modo que la internacionalización legitimará este nuevo campo de estudios en el ámbito académico italiano, habíamos lanzado un llamado en el cuál se hacía refería al concepto de diferencia en sentido amplio (étnica, dis/habilidad, etc.) y dentro de la conferencia dos sesiones se han confrontado con relación entre norma heterosexual, sujeto LGBT y teoría queer. Aunque siendo una conferencia interdisciplinaria, habíamos decidido publicar las actas con la Sociedad Geográfica Italiana, convencidas que podría representar una ocasión para la difusión de una relación ente geografía y diferentes subjetividades sexuales dentro de un contexto fuertemente (hétero)normativo como el de la academia italiana. La elección de incluir solamente textos de geográficos/as (con la excepción de aquella de Mónica Pasquino) para enmarcar mejor la cuestión dentro de la disciplina; pero el problema fue que se trataba casi exclusivamente de los autores extranjeros (Bell, Binnie, Blidon, Hancock), los pocos italianos presentes con los casos de estudio trabajaban en el extranjero, el único referido a un caso era el de Izis y Macchia sobre Torre del Lago Puccini ${ }^{7}$. Incluso siendo positivo que una revista como el Bollettino dedicó un numero especial a esta temática, en su conjunto estas publicaciones no han tenido ningún reconocimiento dentro de la academia italiana, mientras que en otros contextos fue presentado y apreciado: de todos modos era la primera vez que en Italia la geografía se ocupa de tales temáticas. Efectivamente, en Italia, cuando se habla de queer o LGBT se refiere todavía exclusivamente a la sociología; ;es por esto que en un artículo que he escrito para Contemporánea en el 2012 hice mi 'coming out' como geógrafa!

CDF: ¿Cuáles son en tu opinión los principales factores de resistencia que la geografía de género y la de sexualidad encuentran hoy en el contexto italiano? ¿Por qué continúan faltando estudios ad hoc, basados en casos italianos? ¿Por qué, salvo de manera espaciada, en las monografías y en los artículos de geografía urbana, social o económica, no se encuentran referencias e incursiones en la temática de género y de la sexualidad?

RB:Respondo partiendo de la última pregunta; en mi opinión, ;faltan referencias e incursiones porque quién está implicado en esta disciplina no sabe precisamente de que habla a propósito de género y

\section{Cesare Di Feliciantonio}


sexualidad! Efectivamente, dentro de la geografía italiana, el gran problema es que quién está ya dentro no se dedica más a profundizar y a innovar en la actividad de investigación, mientras que la formación doctoral es de bajo nivel. Entonces, sucede que, en muchos casos, quién esta ya dentro no conoce mínimamente, por ejemplo, la literatura sobre la relación entre sexualidad y espacio urbano, o sobre las modalidades con las cuales género y sexualidad influencian la actividad económica. Quien en cambio conoce estas temáticas por lo general no se siente concerné $^{8}$ con la relación que éstas pueden aportar a sus estudios, porque de todos modos faltan, en Italia, el reconocimiento de la relación entre que cada subdisciplina pueda aportar a las otras temáticas de estudio. En relación a esto, los problemas que se plantean son principalmente dos: el primero está constituido de la reticencia hacia la interdisciplinariedad que todavía caracteriza la geografía italiana en su conjunto (a menudo fui 'acusada' de ser una socióloga o una antropóloga en vez de geógrafa). El segundo está relacionado con el hecho de que a conocer y afrontar estas temáticas, son sobre todo los jóvenes académicos, que no tienen acceso a puestos fijos dentro de la universidad; quién por el contrario logra integrarse a la universidad esta temática no la afronta. En efecto, como bien dice Marianne Blidon a propósito del contexto francés, existen temáticas que son todavía absolutamente tabú y que pueden bloquear tu carrera, son aquellas que definiré como dirty topics, que es mejor dejar encerrados en el placard. Por ejemplo, cuando inicié a trabajar sobre postporno, sobre las performances en el espacio público y sobre como se rompen las normas heterosexuales, se me 'sugirió' decir que el foco de mi trabajo era la 'justicia espacial', sin especificar el objeto preciso de mi investigación. En lo que respecta al contexto italiano en su conjunto, estos problemas son seguramente para reconducir en buena parte la influencia y el poder del Vaticano, que perpetúan un fuerte moralismo. Todo esto hizo en modo que solo la geografía de género, entendida como geografía de mujer 'perbene' ${ }^{\prime}$ tenga una cierta legitimidad, en detrimento de todas las otras subjetividades disidentes. Este hizo que la geografía de género se transformase en 'una cosa de mujeres' y como consecuencia, la geografía de la sexualidad fuera solo cosa para gays y lesbianas, por lo tanto quién se ocupa de estos temas viene automáticamente 'tildado' como gay o lesbiana, cosa que es todavía motivo de numerosos problemas en el ámbito académico machista como es el italiano, en el cuál los hombres (heterosexuales) son la mayoría. Se determina así un mecanismo de reproducción, dado que para acceder a la academia se necesita contar con una estrecha relación con alguien que esté ya dentro de la estructura. En cambio, las pocas mujeres que se interesaron por la geografía de género lo han hecho sobre todo como posicionamiento teórico; en cambio, para mí, la geografía de género y la de sexualidad son sobre todo un posicionamiento político, por esto las combatí mucho. Efectivamente, no se rebelaron de frente a conferencias en las cuales el comité científico por estaba integrado nada mas que por hombres o en sesiones plenarias en las cuales no estaba prevista la intervención de mujeres entre las programadas, así como aceptaron que la geografía de género quedara confinada simplemente en sesiones específicas. Esto hizo que la geografía de género y la de sexualidad en Italia sean consideradas como una disciplina exclusivamente para entendidos en la materia, provocando un fuerte retraso en términos de estudio y avances teóricos respecto al contexto internacional.

CDF: La geografía de género y la geografía de la sexualidad, salvo importantes excepciones, son dominantes a nivel internacional, de parte de la producción anglófona. ¿En tu opinion, cuáles beneficios podrían ser aportados gracias a una apertura mayor hacia otros contextos no anglófonos (sobre todo en los casos de estudio) y una toma de conciencia de parte de estudiosos/as que no pertenecen a la academia anglosajona?

RB: Esta para mi es la cuestión clave de nuestra disciplina. Efectivamente, así como la teoría queer y los estudios LGBT, la geografía de género y de la sexualidad nació y se afirmó por primera vez en el mundo anglosajón, pero en los últimos diez años hemos asistido a una proliferación de contribuciones en este campo provenientes de otros académicos y geografía en primer lugar de América Latina, en particular Brasil, pero también de Asia, por ejemplo de parte de académicos chinos y coreanos. Entre otras cosas esta demanda nos ha influenciado fuertemente a Antonella Rondinone y a mí durante la elaboración de la 'Geografia di genere', porque nos decíamos si nosotras mismas, no estábamos reproduciendo una especie imperialismo cultural académico traduciendo nada mas que textos anglosajones. Pero lamentablemente, por culpa de los recursos limitados, no teníamos acceso (en primer lugar lingüístico) a los trabajos de las academias chinas o coreanas y de todos modos, dado que nuestro objetivo era, de algún modo, reconstruir en grandes líneas de investigación de la geografía de género y de la sexualidad, ¡no se podía obviamente evitar la academia anglosajona! En general, en los últimos años asistimos a un número siempre mayor de investigaciones provenientes de

\section{Cesare Di Feliciantonio}


otros contextos y que estudian milieux ${ }^{10}$ diferentes; quedan, por otro lado, dos problemas de orden diverso, el primero está ligado a la difusión limitada de estos trabajos, el segundo está ligado a que estos trabajos no están todavía reconocidos, porque de todos modos están juzgados 'de segundo nivel' respecto a aquellos provenientes de la academia anglosajona. Desde mi punto de vista, el único ámbito académico actualmente en grado de equilibrar, al menos en parte, el peso de la academia estadounidense o inglesa es la de Brasil, sea por lo que respecta la geografía de mujeres, como por la geografía de la sexualidad. Tener casos de estudio que conciernen diversas áreas geográficas es fundamental, porque muestra como la geografía de la sexualidad tiene diferentes declinaciones según los diferentes contextos. Efectivamente, a menudo se refiere a contextos 'en retraso' respecto a los anglosajones, como si fuera una evolución lineal de las cuestiones ligadas al cuerpo y la sexualidad, mientras no es así, las preocupaciones y las declinaciones en los diferentes contextos son diferentes, por esto obviamente permanece la influencia del contexto académico anglosajón, pero las investigaciones siguen después direcciones y líneas de análisis estrechamente ligadas a estos contextos específicos.

CDF: Tu formación está directamente ligada a la geografía cultural y postcolonial, con tus estudios sobre el turismo. ¿Encuentras posibilidades específicas de apertura y encuentro entre esta corriente y los estudios sobre la sexualidad?

RB: Creo que aperturas e influencias recíprocas no son solo posibles, si no que son absolutamente necesarias. En lo que respecta a mi trayectoria personal, no se trató para nada de una ruptura, pues la geografía postcolonial, que fue el punto de partida para mis estudios sobre turismo, tiene muchísimos puntos en comunes con el enfoque queer. En mi trayectoria, el 'punto de transición/pasaje' en el modo en el cual fue representada justamente la teoría queer, la que me llevó hacia la geografía de la sexualidad. En particular, algunos conceptos (identidad híbrida, l'in/between, la caída del binomio, el posicionamiento del proceso de búsqueda) hicieron de este pasaje un continuum $^{11}$ de mis estudios precedentes. Traté de resaltar la continuidad también en los concursos en los cuales participé, justo porque a primera vista parece tratarse de un cambio radical, de ruptura, pero para mí no es para nada así. Para mí es importante demostrar como el estudio del espacio a través del enfoque postcolonial tiene mucho que ver con la sexualidad y, sobre todo, como estos dos enfoques se interpretan en manera profunda y casi irreversible en la realidad social.
CDF: Uno de los hilos conductores de tu producción es el concepto de performance en sentido butleriano. ¿Como has tratado este enfoque a los distintos campos de investigación a los cuales te has dedicado?

RB: Comencé a trabajar sobre el concepto de performance en el marco de mis estudios de/sobre turismo, analizando los actores del turismo como sujetos performativos. En este mismo periodo inicié mis estudios sobre Butler, que fue para mi casi una revelación, por esto decidí dedicarme al concepto de performance dentro des mis investigaciones sobre el turismo. En mis estudios de geografía de la sexualidad, al contrario, el uso del concepto de performance se apoya sobre una sólida tradición teórica, en particular fue fundamental para mi formación el artículo de Bell, Binnie, Cream and Valentine de 1994, en el cuál el concepto de performance asume un rol central en el análisis de los espacios. Recientemente comencé a trabajar sobre en concepto de performance desde un punto de vista teórico, sin declinarlo, después de haber trabajado por mucho tiempo sobre la performance como uso del cuerpo y, en consecuencia, como una ruptura de las normas. En otras palabras, partí del uso del cuerpo al interior de los movimientos y manifestaciones públicas de reivindicaciones LGBT, mientras en los últimos dieciocho meses estoy trabajando sobre performances consideradas en el trabajo de carácter artístico - militante en los espacios urbanos a través el movimiento político del postporno. El concepto de performance tiene diferentes posibilidades de aplicación, no existe una manera univoca de entenderlo, por lo cual, por ejemplo, la relación de las lesbianas con la playa, que representa uno de mis intereses de investigación, puede ciertamente leerse como performance de género, aunque si no es necesariamente consciente.

CDF: Tu principal interés de investigación es actualmente las performances postporno, temática que has buscado de profundizar dentro de la academia francesa, dado que actualmente trabajas en Francia. ¿Puedes explicarnos mejor como se realiza tu investigación sobre postporno y que relaciones han provocado tus investigaciones?

RB: Mi trabajo sobre el postporno tuvo inicio casi por casualidad mientras mis investigaciones se ocupaban de la relación entre espacio público y héteronormatividad y estaba en la búsqueda de posibles respuestas de como es posible concretar la héteronormatividad en los espacios públicos. En la inauguración de 'Female Extreme Body Art Festival', 
evento que fue realizado en Roma hace ya algunos años, participé a la proyección de un documental sobre el postporno, argumento que en aquel periodo todavía no sabía absolutamente nada, en el cual las performers se exhibían en un espacio que aparecía a todos los efectos público. Me dije que capaz fuera eso que estaba buscando, porque las imágenes mostraban un uso sexual y sexuado del cuerpo para romper con la héteronormatividad de la sociedad. Recuerdo que la primera tarde que vi un espectáculo postporno en vivo, cuando volví a casa escribí inmediatamente un artículo, que después fue publicado en el sitio www.luogoespazio.info, en la medida que quería plasmar aquello a lo que había asistido y hacerlo al interior de una comunidad, como junto a otros jóvenes geógrafos había creado un sitio para difundir una visión del pensamiento geográfico en relación a los hechos de actualidad. Para mí, las performances postporno están directamente ligadas con la geografía en el momento en el cual se trata de acciones que van a romper, a través del uso de una fisicidad que podríamos definir como extrema, la héteronormatividad del espacio público; en realidad, el movimiento postporno no condena solamente la norma heterosexual, si no la norma en sí. En lo específico, en mis investigaciones las performances postporno en el espacio público, se encuentran en la zona límite entre la legalidad y la ilegalidad, en sentido que, son estas, en mi opinión, que a largo plazo determinan los cambios. Cito a propósito de esto el ejemplo de dos sitios web para la promoción turística de Barcelona, en el cual se refiere explícitamente a Diana pornoterrorista y a la escena postporno, particularmente fuerte en Barcelona. Asistimos por lo tanto al tentativo de apropiación de parte del sistema de este movimiento que tiene por el contrario bases anarquistas, para 'caracterizar' a Barcelona casi como exótica. Esto muestra como bastaron los momentos en los cuales Diana y las otras habían realizado performances en las ramblas para dejar una marca; otra performance que desde mi punto de vista tuvo un impacto fuerte es aquella que realizaron en el Vaticano en el 2009, en la cual trajeron una estatua de la Virgen que se encontraba al exterior, en un espacio que es público (¡dentro de lo que se pueda definir como público un espacio del Vaticano!). Mi análisis se focaliza particularmente en la relación de estos cuerpos con el espacio y las contemporáneas reacciones de las personas que asisten a la performance. En lo que se refiere a mi trabajo en Francia, donde me encuentro actualmente, el proyecto de investigación trataba otra temática, el grupo de investigación al cual pertenezco me permitió continuar a trabajar paralelamente también sobre postporno, y es en efecto sobre esto que presento mi proyecto al CNRS (Centre Nationale de la Recherche Scientifique) $)^{12}$ el año pasado. Fui caracterizada classée, es decir entré en las graduatorias finales, pero no lo gané, el componente espacial fue juzgado como no haber sido lo suficientemente resaltado, pero al mismo tiempo mi investigación fue caracterizada como demasiado poussée ${ }^{13}$. En su conjunto, el contexto académico saludó con interés mis investigaciones, no tanto como para integrarme en su seno. Un interés particular viene dado al hecho que yo misma he comenzado a realizar performances, en las cuales el centro es mi cuerpo desnudo, haciendo ésto no como una performer sino como una académica que se performa. Quisiera proponer antes o después una presentación/performance en un congreso, desnudándome mientras hablo sobre el postporno. La idea es romper el binomio performers/académico $\mathrm{y}$, entonces paralelamente el de espacio de la performance, en el cual el desnudo pude ser aceptado porque se considera artístico, y espacio de la producción del conocimiento, en el cual se debe permanecer adentro de una determinada norma para poder ser escuchado, reafirmando la contraposición entre espacio de la cabeza y espacio del cuerpo. Si en Inglaterra, vemos el caso de Lazlo Pearlman, es posible ser investigador y performers al mismo tiempo, aquí en Francia esto tiene un juicio negativo porque compromete la 'distancia' en el proceso de investigación al cual la academia francesa esta todavía muy ligada. Desde mi punto de vista, esto demuestra claramente que en Francia prevalece un conflicto no resuelto entre militancia y academia. ¡ $\mathrm{Al}$ contrario en lo que respecta Italia, de costumbre la mayor parte de la gente reacciona riendo cuando ilustro mi trabajo! Como hice alusión precedentemente, el hecho que se me aconsejara presentar mis investigaciones como encuadradas en el campo de la 'justicia espacial' elocuente 'perbenismo'14 de una cierta izquierda al interior de la geografía italiana, en la cual se puede trabajar sobre temas de conciencia social y política, pero solo cuando se trata de personas 'decentes'/'perbene'! ()

1 Traducción de Florencia Lifredo

2 Postdoctorado.

3 Italiano.

$4 \quad$ La ciudad de las mujeres 
$5 \quad$ Asociación de geografos italianos.

6 Boletín de la Sociedad Geografíca Italiana.

7 Torre del Lago Puccini es la localidad balnearia más importante para el turismo LGBT de verano en Italia.

8 Involucrada.

9 Decentes. 'Donna perbene' es una expresión de la lengua italiana que apunta a afirmar la respetabilidad social y moral de las mujeres solamente si responden a un cierto modelo de mujer (burguesa).

$10 \quad$ Ambiente.

11 Continuo

12 Centro Nacional de investigación científica.

$13 \quad$ Forzada.

$14 \quad$ Ver nota $n^{\circ} 8$

\section{Bibliografía}

ARENA, Gabriella. Geografia al Femminile. Milano: Unicopli, 1990.

BELL, David; BINNIE, Jon; CREAM, Julia; VALENTINE, Gill. All hyped up and no place to go. Gender, Place and Culture: A Journal of Feminist Geography, v. 1, n. 1, p. $31-47,1994$.

BORGHI, Rachele. Hai detto geografia? Dell'intricato rapporto tra studi lgbtiq e spazio. Contemporanea, v. 15, n. 4, p. $703-709,2012$.

BORGHI, Rachele; Celata, Filippo. Turismo Critico. Milano: Unicopli, 2009.

BORGHI, Rachele; RONDINONE, Antonella. Geografia di genere. Milano: Unicopli, 2009.

BORGHI, Rachele; SCHMIDT DI FRIEDBERG, Marcela. Lo spazio della differenza. Bollettino della Geografia Italiana, vol. IV, n. 13, 2011.

CORTESI, Gisella. Luoghi e identità di genere. Geotema, v. 33, p. 3 - 11, 2007.

CORTESI, Gisella; GENTILESCHI, Maria. Donne e geografia. Studi, ricerche, problemi. Milano: Franco
Angeli, 1996.

CORTESI, Gisella; CRISTALDI, Flavia; DROOGLEEVER FORTUIJN, Joos. Gendered Cities: identities, activities, networks. A life-course approach. Roma: Società Geografica Italiana, Roma, 2004.

CORTESI, Gisella; CRISTALDI, Flavia; DROOGLEEVER FORTUIJN, Joos. La città delle donne. Un approccio di genere alla geografia urbana. Bologna: Pàtron, 2006.

DELL'AGNESE, Elena; RUSPINI, Elisabetta. Mascolinità all'italiana. Costruzioni, narrazioni, mutamenti. Torino: UTET, 2007.

GARCIA RAMON, Maria Dolors; MONK, Janice. Gender and geography: World views and practices. Belgeo, v. 3, p. 247 - 260, 2007. 